\title{
Shock wave synthesis and processing of high temperature superconductors with defect microstructures
}

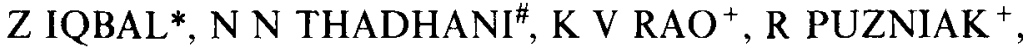 \\ R SHARMA $^{* *}$, B L RAMAKRISHNA**, H ECKHARDT* and \\ F J OWENS ${ }^{++}$ \\ *Allied-Signal Inc., Corporate Technolugy. Morristown NJ 07962, USA \\ \#CETR, New Mexico Institute of Mining and Technology, Socorro NM 87801, USA \\ + Department of Solid State Physics, Royal Institute of Technology, Stockholm, Sweden \\ **Department of Chemistry and Center for Solid State Science, Arizona State University, \\ Tempe AZ 85287, USA \\ ${ }^{++}$Department of Physics, Hunter College. City University of New York, New York 10011, \\ USA, and ARDEC, Picatinny NJ 07801. USA
}

\begin{abstract}
The tetragonal $\left(T_{1}=55 \mathrm{~K}\right)$ and orthorhombic (non-superconducting) $\mathrm{Tl}_{2} \mathrm{Ba}_{2} \mathrm{CuO}_{6}(\mathrm{Tl} 2201)$ phases have been synthesized by a ca $20 \mathrm{GPa}$ planar shock wave in a microsecond time frame. Because of local rapid quench rates (up $1010^{6} \mathrm{~K} / \mathrm{s}$ ) defects related to metastable phases are frozen in the sample. In the 2201 phase the predominant defect identified by high resolution lattice imaging corresponds to a $\mathrm{Tl}-\mathrm{Ba}-\mathrm{Cu}-\mathrm{Tl}-\mathrm{Cu}(\mathrm{Tl} 1212)$ phase which is metastable but can be synthesized via a low temperature reaction. Defects of this type may account for the enhanced flux trapping observed in the material using field modulated microwave absorption. Attempts at shock synthesizing the more complex $\mathrm{Tl}_{2} \mathrm{Ba}_{2} \mathrm{CaCu}_{2} \mathrm{O}_{8}$ and $\mathrm{Tl}_{2} \mathrm{Ba}_{2} \mathrm{Ca}_{2} \mathrm{Cu}_{3} \mathrm{O}_{10}$ phases are also discussed. Shock processing pre-synthesized $\mathrm{YBa}_{2} \mathrm{Cu}_{3} \mathrm{O}_{7}$ powder in the radial geometry followed by an $\mathrm{O}_{2}$ anneal at $890 \mathrm{C}$ produces neartheoretical density cylinders that sustain inter-grain critical currents at zero field of 1350 and $750 \mathrm{amps} / \mathrm{cm}^{2}$ at 60 and $77 \mathrm{~K}$ respectively. The magnetic field dependence of the critical current and the magnitude of flux-pinning in this material relative to sintered pellets are enhanced by a factor of 2-3. Preliminary investigations of the defect microstructure of this material are discussed.
\end{abstract}

Keywords. Shock wave synthesis; superconductors; defect microstructures.

\section{Introduction}

We have been studying the application of shock waves in different geometries and pressure ranges as a method of producing highly dense bulk superconductors with welldefined defects which can act as flux pinning centers (Iqbal 1988; Iqbal et al 1989a,b). Related work using a variety of experimental arrangements has been carried out by other groups in USA, Japan and USSR (Morosin et al 1989 and references therein; Murr et al 1989; Syono et al 1989; Nesterenko 1989). Shock waves produced in a gas gun or in an explosive detonation front provide dynamic pressures ranging from 1 to $100 \mathrm{GPa}$ with durations of a few microseconds. Local temperatures in the solid can rise by a few thousand degrees as indicated by two-dimensional simulations for different packing densities (Thadhani 1988). This is followed by extremely fast quench rates of up to $10^{6} \mathrm{~K} / \mathrm{s}$ which allows the fabrication of metastable or non-equilibrium structures.

In this paper we will discuss experiments carried out in the 10 to $25 \mathrm{GPa}$ regime aimed at shock-synthesizing the Tl-based superconductors with built-in novel defects. Initial results of some of this work have been reported by Iqbal et al (1989b). Previous shock synthesis attempts have been made in the $\mathrm{LaSrCuO}, \mathrm{YBaCuO}$ and $\mathrm{BiSrCaCuO}$ 
systems, with sizable conversions to the superconducting phase structure achieved only in the case of the La compound (Morosin et al 1989). However, the samples still had to be annealed under $\mathrm{O}_{2}$ to achieve the correct superconducting stoichiometry. We also report on the shock-induced modification of pre-synthesized $\mathrm{YBa}_{2} \mathrm{Cu}_{3} \mathrm{O}_{7}(\mathrm{Y} 123)$ powder in the pressure regime below $10 \mathrm{GPa}$ and in a radial geometry. The shockmodified material when $\mathrm{O}_{2}$-annealed provided samples with critical-state properties that were improved compared with those of conventionally processed material.

\section{Experimental aspects}

The set-up used for the synthesis experiments consists of a steel flyer plate which is explosively accelerated over a $10-20 \mathrm{~mm}$ stand-off distance and impact powders contained in steel capsules embedded in the cavities of a steel recovery fixture. Impact planarity is achieved via the use of a plane wave shock lens arrangement (Thadhani 1988). The precursor powders were packed at typically ca. $60 \%$ of theoretical density and the impact plate is monitored during the experiment by a high speed camera.

The consolidation-modification experiments were performed in a cylindrical geometry which utilizes radial grazing angle shock loading. The precursor powder (packed to ca. $45 \%$ density for these experiments) was placed in a thin-walled copper tube (outer diameter of $2.5 \mathrm{~cm}$ ). The explosive was packed into an outer concentric tube and ignited from the top to set up a cylindrical convergent shock wave that propagates through the powder resulting in near theoretical density consolidation.

The Tl-based precursors for the shock synthesis experiments consisted of finely ground powders of $\mathrm{Tl}_{2} \mathrm{O}_{3}$ and a matrix material (to which unreacted $\mathrm{BaO}_{2}$ was added in some experiments). For synthesis of $\mathrm{Tl}_{2} \mathrm{Ba}_{2} \mathrm{CuO}_{6}(\mathrm{Tl} 2201)$ phase the matrix material was of nominal composition $\mathrm{Ba}_{2} \mathrm{Cu}_{3} \mathrm{O}_{x}$ which was prepared by firing $\mathrm{BaCO}_{3}$ and $\mathrm{CuO}$ at $930 \mathrm{C}$ in air for $30 \mathrm{~h}$. Experiments on the synthesis of the T12201 phase were performed using precursor powders of nominal $\mathrm{Tl}-\mathrm{Ba}-\mathrm{Cu}$ atomic ratios of $1-2-3,2$ 2-3 and 2-2-1. The 221 ratio was achieved by adding $\mathrm{BaO}_{2}$. Experiments aimed at preparing the $\mathrm{Tl}_{2} \mathrm{Ba}_{2} \mathrm{CaCu}_{2} \mathrm{O}_{2}$ ( $\left.\mathrm{Tl} 2212\right)$ and $\mathrm{Tl}_{2} \mathrm{Ba}_{2} \mathrm{Ca}_{2} \mathrm{Cu}_{3} \mathrm{O}_{10}$ ( $\mathrm{Tl}$ 2223) phases used a matrix of composition $\mathrm{Ba}_{2} \mathrm{Ca}_{2} \mathrm{Cu}_{3} \mathrm{O}_{x}$ prepared by firing $\mathrm{BaCO}_{3}, \mathrm{CaCO}_{3}$ and $\mathrm{CuO}$ at $875 \mathrm{C}$ for $20 \mathrm{~h}$ in air. Firing the matrix mixture above $900 \mathrm{C}$ resulted in partial melting and difficulty in obtaining a smoothly mixed precursor powder. Experiments were carried out with precursors of $\mathrm{Tl}-\mathrm{Ba}-\mathrm{Ca}-\mathrm{Cu}$ atomic ratios of $1-2-2-3$ and $2-2-2-3$.

The precursor powder for the shock consolidation-modification experiments was conventionally synthesized Y123 powder of average grain size of $1-5 \mu \mathrm{m}$ (obtained from Superconductive Components Inc). The powder did not contain impurity phases down to a $1 \%$ volume level as checked by $\mathrm{X}$-ray diffraction and (for paramagnetic phases) down to the ppm level as checked by EPR.

\section{Synthesis, results and discussion}

Shock synthesis of $\mathrm{Tl} 2201$ with $\geq 85 \%$ conversion was achieved at pressures approaching $20 \mathrm{GPa}$ using the planar geometry and 123 and 221 precursor powders prepared as described in $\$ 2$. The $X$-ray patterns are shown in figure 1 . From the patterns it is evident that the near-tetragonal $(c=23.16 \AA)$ phase is obtained from 


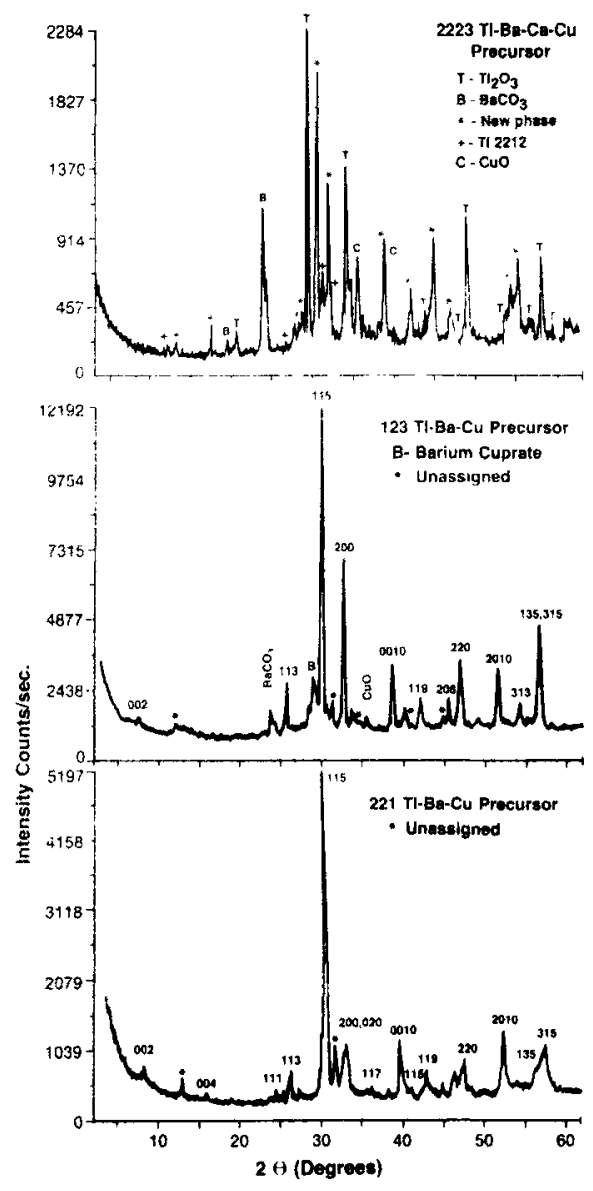

Figure 1. Powder X-ray patterns from shock products obtained from Tl-based precursor compositions indicated on the top corner of each pattern. The numbers labelling the reflections are the $h k l$ indices.

Tl-deficient 123 precursors, whereas the orthorhombic phase was obtained from the stoichiometric 221 precursor. Note that the latter precursor contained $\mathrm{BaO}_{2}$ and all experiments were performed in a reduced oxygen atmosphere. The product obtained from the 223 precursor showed a large fraction of unconverted $\mathrm{Tl}_{2} \mathrm{O}_{3}$ and a minority fraction of the T1 2201 phase. The diffraction patterns indicated the presence of a new phase which will be discussed below. Both the products from 123 and 223 precursors showed superconductivity in the as-synthesized state (figure 2 ). $T_{c}$ (zero) values are 55 and $20 \mathrm{~K}$ respectively for the 123 and 223 products. Diamagnetic fractions are low for the 223 product but greater than $20 \%$ for the Tl-deficient 123 product, which in addition shows a diamagnetic onset at $70 \mathrm{~K}$. Consistent with the work of Hewat et al (1988), the orthorhombic phase obtained from the 221 product is not superconducting down to $4 \mathrm{~K}$.

Analytical TEM (transmission electron microscopy) showed the composition of the 221 product to be close to that of the Tl 2201 phase. However, the 123 product microcrystals showed a $\mathrm{Tl} \mathrm{Ba}-\mathrm{Cu}=2-2-2$ composition. It is likely that the excess $\mathrm{Cu}$ 


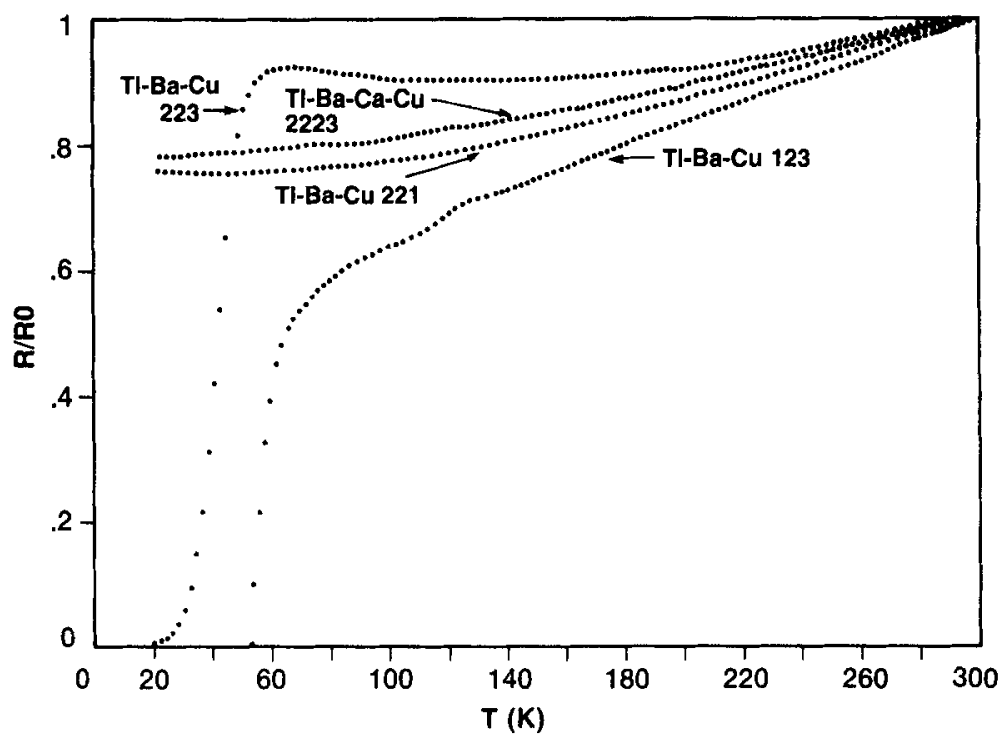

Figure 2. Normalized resistivity data $(50 \mathrm{~mA}$ current) for shock products obtained from $\mathrm{T} 1$ $\mathrm{Ba}-\mathrm{Cu}=123,223,221$ and $\mathrm{T} 1-\mathrm{Ba}-\mathrm{Ca}-\mathrm{Cu}=2223$ precursors.

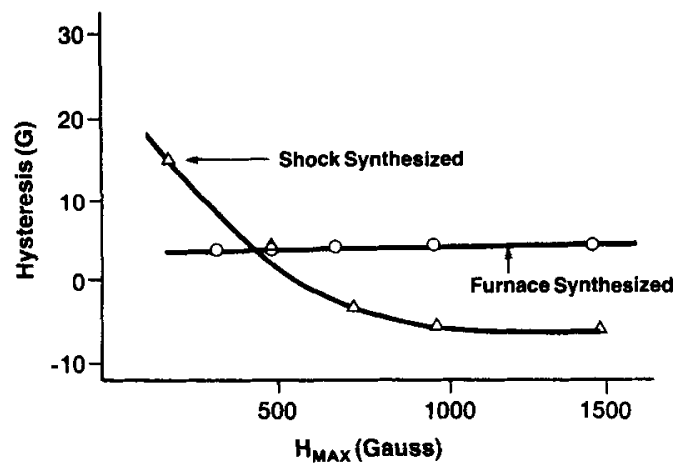

Figure 3. Peak to peak hysteresis at $70 \mathrm{~K}$ (for shock and conventionally synthesized $\mathrm{Tl}_{2} \mathrm{Ba}_{2} \mathrm{CuO}_{6}$ ) of the magnetic field positions of the non-resonant microwave absorption for decreasing and increasing field scans versus the maximum magnetic field applied to the sample.

is associated with poorly crystallized $\mathrm{CuO}$ coating the microcrystals. High resolution lattice imaging of the 123 product reveals intergrowths of the single Tl-layer and nonsuperconducting $\mathrm{TlBa}_{2} \mathrm{CuO}_{5}$ phase, but in addition extensive defects of the type- $\mathrm{Ba}-$ $\mathrm{Cu}-\square-\mathrm{Cu}-\mathrm{Ba}-$ are observed only in the 123 and not in the 221 product. Computer simulations indicate partial Tl-occupancy between the two copper layers of the defect. The defect would correspond to metastable $\mathrm{TlB} \mathrm{a}_{2} \mathrm{TlCu}_{2} \mathrm{O}_{7}\left(\mathrm{Tl} 1212^{*}\right)$. We attempted to synthesize this phase by conventional low temperature firing under $\mathrm{O}_{2}(750 \mathrm{C}$ for $1 \mathrm{~h}$ ) of a stoichiometric precursor consisting of $\mathrm{Tl}_{2} \mathrm{O}_{3}$ and $\mathrm{BaCuO}_{2}$. Partial formation is observed of a new phase with some X-ray lines corresponding to the unknown phase 
pattern of shock synthesized T1 2201 (figure 1). Under the present synthesis conditions this phase is weakly semiconducting. Further work on this novel phase is in progress.

Estimates of the transport critical current of the 123 product were made via the AC susceptibility method (see below) and found to be low, probably due to sample porosity caused by $\mathrm{O}$ and $\mathrm{Tl}$ diffusion during the synthesis process. Filling the pores with $\mathrm{Ag}$ may be necessary to achieve useful critical current densities. However, the hysteresis of the field position of the non-resonant microwave absorption below $T_{c}$, which is related to flux-trapping in the critical state (Owens 1989; Owens and Iqbal 1990) shows an increase for the shock-synthesized $\mathrm{Tl} 2201$ compared with conventionally prepared material, as shown in figure 3 for different maximum applied fields. This suggests that defects of the type discussed above play a role in enhancing the pinning forces.

Synthesis experiments aimed at fabricating the 3 copper oxide layer $125 \mathrm{~K}$ phase by the methods discussed above were not entirely successful. The increased multicomponent nature of the precursor powder probably hinders the solid-state reaction processes. An X-ray diffraction pattern of the 2223 product is shown in figure 1. A small fraction of the $\mathrm{Tl} 2122$ phase is indeed formed together with an unknown phase and a large fraction of unreacted $\mathrm{Tl}_{2} \mathrm{O}_{3}$. The resistivity data (figure 2) show no indication of superconductivity down to $10 \mathrm{~K}$, indicating that the $\mathrm{Tl} 2122$ phase formed has its oxygen sub-lattice disordered as a result of the shock wave (this is in contrast to the more robust behaviour of the Tl 2201 phase). Similar results are obtained for experiments using the 1223 precursor.

\section{Shock consolidation-modification}

Shock consolidation-modification experiments were carried out in the cylindrical geometry at $10 \mathrm{GPa}$ using Y123 powder. The as-shocked cylinders ( $290 \%$ theoretical density) were machined into bars and annealed in flowing $\mathrm{O}_{2}$ for $12 \mathrm{~h}$ at $890 \mathrm{C}$ followed by an $8 \mathrm{~h} \mathrm{cool}$. The resistivity data for these shock-annealed samples showed a drop at $93 \mathrm{~K}$ to nominally zero resistance with a transition width of $c a .1 \mathrm{~K}$. DC SQUID magnetization data (figure 4 a) show $100 \%$ shielding at $4 \mathrm{~K}$ with a sharp onset at $93 \mathrm{~K}$ for an applied field of $20 \mathrm{Oe}$. Meissner signals are lower by a factor of 8 compared with a factor of 2 decrease for the as-shocked and conventionally sintered precursor powder. Additionally, for the shock + annealed sample the remnant field obtained on turning off the applied DC field corresponds to the zero field moment. Ail this indicates enhanced flux trapping in the shock + annealed sample. This is also evident in the highfield magnetization hysteresis loops in fields up to $20 \mathrm{kOe}$, where the hysteresis at $20 \mathrm{kOe}$ for the shock + annealed compared with the as-shocked samples are enhanced by a factor of $c a .1 .5$ (see figure $4 \mathrm{~b}$ ).

Inter-grain critical currents at different temperatures were obtained by two noncontact methods. In the first method the real and imaginary (loss) components of the AC susceptibility at different temperatures below $T_{c}$ were used as described by Chen et al (1989). In the second method (Rao 1989) low DC field (in the vicinity of $\mathrm{H}_{c 1}$ ) hysteretic loops were obtained and $J_{c}$ 's calculated for fields up to $c a$. 200 Oe using Bean's equation, the slab thickness and the measured hysteresis. Both methods gave nearly the same values of $J_{c}: 3250 \mathrm{amps} / \mathrm{cm}^{2}$ at $4 \mathrm{~K} .1350 \mathrm{amps} / \mathrm{cm}^{2}$ at $60 \mathrm{~K}$ and $750 \mathrm{amps} / \mathrm{cm}^{2}$ at $77 \mathrm{~K}$ in zero field. The value at $77 \mathrm{~K}$ is comparable to that reported by Dwir et al (1989) for conventionally sintered Y 123 -Ag composites and a factor of 1.5 to 2 better than 

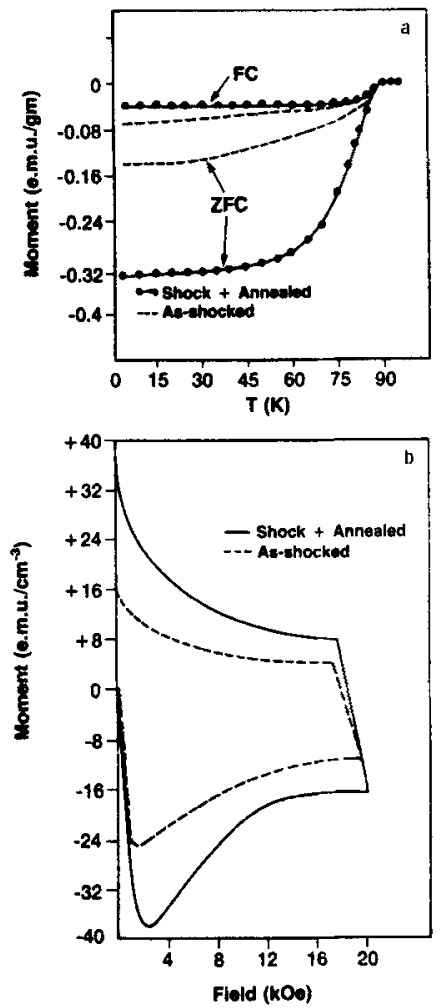

Figure 4. a. Magnetic moment versus temperature at $20 \mathrm{Oe} \mathrm{DC}$ field for as-shocked and shock + annealed $\mathrm{YBa}_{2} \mathrm{Cu}_{3} \mathrm{O}_{7}$. FC and $\mathrm{ZFC}$ represent field-cooled and zero field-cooled data respectively. b. Magnetic moment versus field hysteresis loops for the two samples above at $4 \mathrm{~K}$.

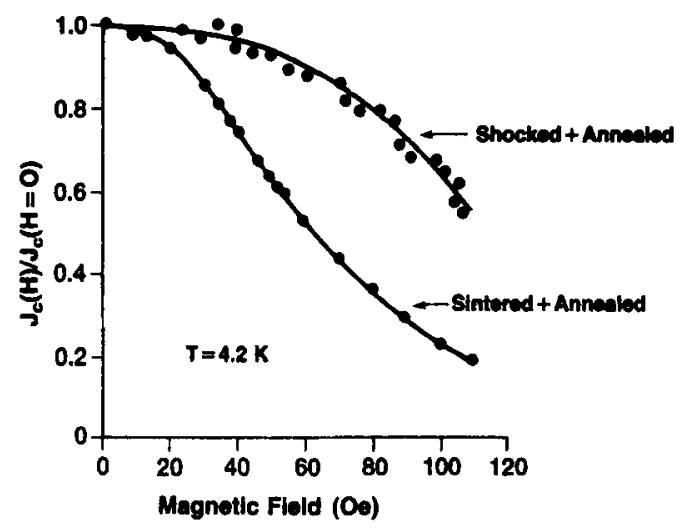

Figure 5. Normalized transport $J_{c}$ at $4.2 \mathrm{~K}$ for shock + annealed and conventionallysintered $\mathrm{YBa}_{2} \mathrm{Cu}_{3} \mathrm{O}_{7}$. 


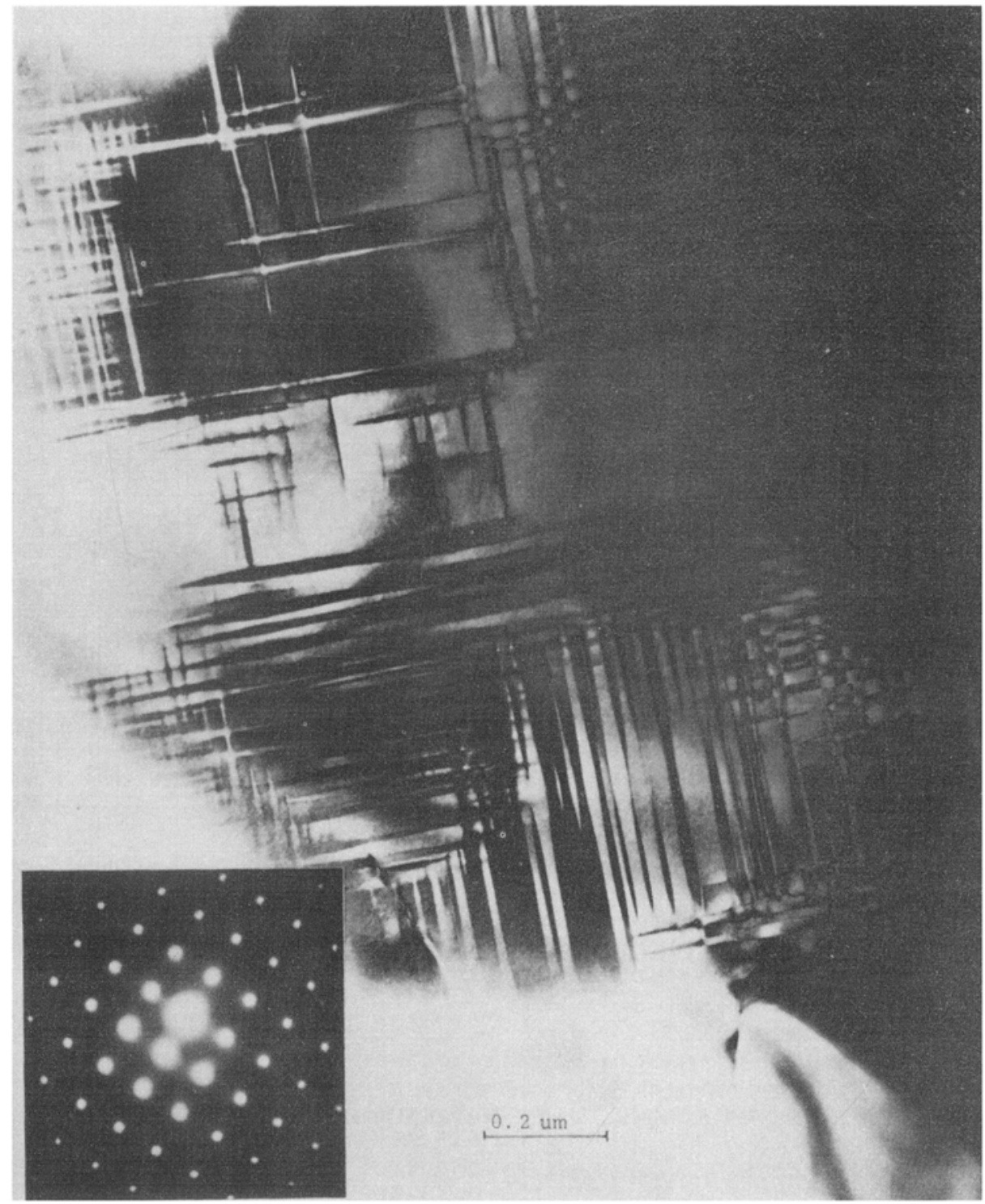

Figure 6. Transmission clectron micrograph of shock + anncalcd $\mathrm{YBa}_{2}\left(\mathrm{C}_{3} \mathrm{O}_{7}\right.$ microcrystal together with the correspondug 001 settung electron diffraction pattern.

typical sintered Y123. The $J_{c}$ values at zero field normalized to the values at higher fields at $4 \mathrm{~K}$ for the shock + annealed and sintered samples are plotted in figure 5 for DC fields up to ca. $120 \mathrm{Oe}$. It is evident that the drop off with field is much lower for the shock + annealed sample and $J$, is a factor of 3 higher at 100 Oe. This is consistent with the data showing enhanced flux trapping and suggests that coupled with grain orientation the shock method may provide $J$,'s approaching those of melt textured material. 
We have also examined the microstructure of the shock + annealed samples in some detail. X-ray diffraction shows a small decrease in the orthorhombic splitting and a shoulder appears near $80 \mathrm{~K}$ in susceptibility data taken at fields near 30 Oe. This suggests the existence of a metastable $\mathrm{O}$-sublattice or $\mathrm{Y}$ at Ba sites (Iqbal et al 1988) which might actually degrade bulk transport $J_{c}$ in our material at $77 \mathrm{~K}$. In addition TEM shows the existence of a large number of microcrystals with interpenetrating twins and dislocations as is evident in figure 6 . The electron diffraction pattern shows no indication of superlattice reflections. Comparison with as-shocked material shows a clear-cut growth of interpenetrating twins on annealing. It is likely that the a nealing step releases shock-induced strain via the formation of the microstructure shown in figure 6 which provides the sites for flux pinning. These sites may also be the seat of atomic scale defects which are being studied by lattice imaging techniques.

\section{References}

Chen D X, Nogues J and Rao K V 1989 Cryogenics 29800

Dwir B, Pavuna D, Affronte M, Berger H and Tholence J L 1989 J. Supercond. 2419

Hewat A W, Bordet P, Capponi J J, Chaillout C, Chenavas J, Godinho M, Hewat E A, Hodeau J L and Marezio M 1988 Physica C156 369

Iqbal Z 1988 Proc. 2nd Workshop on industrial application feasibility of dynamic compaction technology, (eds) A B Sawaoka, M Fujita, S Fujiwara, N Setaka and Y Syono (Tokyo: Institute of Technology) p. 75

Iqbal Z, Reidinger F, Bose A. Cipollini N, Taylor T J, Eckhardt H, Ramakrishna B L and Ong E W 1988 Nature (London) 331326

Iqbal Z, Thadhani N N, Chawla N, Rao K V, Skumryev S, Ramakrishna B L, Sharma R, Eckhardt H and Owens F J 1989a Proc. APS Topical Conference on shock compression of condensed matter (ed) S C Schmidt (in press)

Iqbal Z, Thadhani N N, Chawla N, Ramakrishna B L, Sharma R, Rao K V, Skumryev S, Reidinger F and Eckhardt H 1989b Appl. Phys. Lett. 552339

Morosin B, Venturini E L, Graham R A and Ginley D S 1989 Synthet. Met. 33185

Murr L E, Niou C S, Jin S, Tiefel T H, James A C W P, Sherwood R C and Siegrist T 1989 Appl. Phys. Lett. 551575

Nesterenko V F 1989 Bull. Am. Phys. Soc. 341699

Owens F J 1989 Synthet. Met. 33225

Owens F J and Iqbal Z 1990 Physica C166 231

Rao K V 1989 (private communication - to be published)

Syono Y, Nagoshi M, Suzuki T, Kusaba K, Tokiwa A, Kikuchi M and Fukuoka K 1989 Bull. Am. Phys. Soc. 341703

Thadhani N N 1988 Adv. Mater. Manufacturing Process 3493 